\title{
O ESPAÇO-TEMPO DA BIBLIOGRAFIA E DO DOCUMENTO: REFLEXÕES SOBRE EPISTEMES E MEDIAÇÕES
}

\author{
EL ESPACIO-TIEMPO DE LA BIBLIOGRAFÍA Y DEL \\ DOCUMENTO: REFLEXIONES SOBRE EPISTEMES Y \\ MEDIACIONES
}

Maira Cristina Grigoleto ${ }^{a}$

\begin{abstract}
RESUMO
Introdução: Trata o espaço-tempo da Bibliografia e do documento a partir da noção de saberes sujeitados, direcionando entendimentos sobre as epistemes histórica e científica no percurso constitutivo de saberes e práticas. Objetivo: Visa discutir a questão da racionalidade e da regularidade nos processos de institucionalização; e refletir sobre as potencialidades para a exploração da Bibliografia e do documento, atentando para os percursos de reconhecimento, validação, manutenção e possibilidades de alocações. Metodologia: Foi realizada revisão de literatura com base nas abordagens da Teoria do Documento e da Teoria Records Continuum. Resultados: Destaca movimentos de sujeição da Bibliografia por meio de ordenações funcionais e organizações sistemáticas da Bibliologia e da Documentação. Conclusões: Entende a Bibliografia e o documento como dispositivos de saber/poder/fazer (dispositivos de mediação) ao observar as características materiais e relacionais (produtos e processos), tendo como alicerce o gesto bibliográfico.
\end{abstract}

Descritores: Bibliografia. Documento. Epistemologia. Mediação. Gesto Bibliográfico.

\footnotetext{
a Doutora em Ciência da Informação pela Universidade Estadual Paulista Júlio de Mesquita Filho (Unesp), professora adjunta da Universidade Federal do Espírito Santo (Ufes). E-mail: magrigo@hotmail.com
} 


\section{INTRODUÇÃO}

A noção de saberes sujeitados, apropriada do pensamento de Michel Foucault (2005), conduziu as reflexões sobre epistemes e mediações para abordar o espaço-tempo da Bibliografia e do documento.

Esta formulação foi realizada em atenção às colocações de Araújo (2015, p. 122), a partir das reflexões de Alfredo Serrai, de que os debates sobre a Bibliografia não estão esgotados, mas exigem novos olhares sobre problemas antigos. Além disso, atentou-se para a necessidade de compreender "a dinâmica flutuante da disciplina bibliográfica" para refundações teóricas. Do mesmo modo, considerou-se a importância deste entendimento para os estudos da Ciência da Informação e da Documentação, que têm abordado a Bibliografia como uma "disciplina historicamente distante e mencionada do ponto de vista meramente cronológico".

A partir destes apontamentos, alguns questionamentos são colocados: 1) Quais os enfrentamentos e as lutas que certas ordenações funcionais, que certas organizações sistemáticas de saberes tiveram como objetivo mascarar?; 2) Como compreender os processos de desqualificação de saberes, estabelecidos por meio da hierarquização dos conhecimentos e das ciências, no percurso para a institucionalização de certos discursos científicos em detrimento de outros? 3) Quais vanguardas teórico-políticas foram entronizadas para destacá-las de todas as outras formas maciças, circulantes e descontínuas de saber? 4) Quais vetores de poder indicam para insurreição de saberes sujeitados? (FOUCAULT, 2005).

Para abordar estas questões foi realizada revisão de literatura sobre a Bibliografia com base na Teoria do Documento e na Teoria Records Continuum (LUND, 2009; MCKEMMISH, 2017).

Em um primeiro momento, pela abordagem da Teoria do Documento, buscou-se entendimentos sobre o lugar institucional da Bibliografia, estabelecido em meio a agenciamentos e jogos de poder entre saberes e práticas da Bibliografia, Bibliologia e Documentação a partir e sobre o documento. Os estudos de Araújo (2015) e Saldanha (2015) sobre os percursos de Conrad 
Gesner e Gabriel Piegnot, respectivamente, auxiliaram na reflexão sobre as epistemes histórica e científica e no desenvolvimento da hipótese da Bibliografia como saber sujeitado.

A Teoria Records Continuum, em um segundo momento, auxiliou na observação das dinâmicas e regularidades do saber/poder/fazer da Bibliografia a partir e sobre o documento ao considerar as dimensões múltiplas e as potencialidades para a insurreição pelo gesto bibliográfico e pelas mediações. Para tanto, recorreu-se as contribuições dos seguintes autores: Crippa (2015a, 2015b e 2016), Menezes (2015) e Ortega e Carvalho (2017).

Portanto, pelo diálogo estabelecido entre a Teoria do Documento e a Teoria Records Continuum, foi possível o desenvolvimento das reflexões sugeridas considerando os seguintes aspectos: lugar, espaço e tempo. Por meio deste percurso, é que se encontra a fundamentação para pensar as condições da Bibliografia e do documento como dispositivos em diferentes conjunturas, temporalidades e formas de relações.

\section{BIBLIOGRAFIA E DOCUMENTO: A QUESTÃO DOS SABERES SUJEITADOS}

A estruturação, fundamentação, desenvolvimento, reconhecimento e validação da Bibliografia, tanto pela esfera bibliotecária quanto pela esfera material, demonstra o seu status disciplinar. A partir do século XVI e de Conrad Gesner, ocupa-se dos aspectos semânticos dos documentos, articulando sua fisicalidade e os saberes inerentes a eles. Tem como característica o tratamento documental por meio de abordagens teóricas e práticas (ARAÚJO, 2015).

Pela esfera bibliotecária, verificam-se os fundamentos da disciplina e sua associação com a

[...] produção e difusão de documentos (instrumentos) de registro, organização, representação, acesso e mediação da cultura escrita, notadamente os inventários, catálogos e bibliografias que foram produzidos e aperfeiçoados, seja na era manuscrita ou impressa (ARAÚJO, 2015, p. 120). 
Em relação à esfera material, reside o domínio que auxilia na construção do conceito de Bibliografia e no entendimento de seu direcionamento para "o estudo da fisicalidade do livro, considerando a ideia de que a forma do livro/documento determina o seu sentido e seus modos de apropriação" (ARAÚJO, 2015, p. 120).

A Bibliografia, disciplina que antecede a Documentação, Biblioteconomia e Ciência da Informação, é posterior aos objetos que designa, quais sejam: "bibliografias, listas e repertórios". Como tal, estrutura-se a partir da correlação entre a produção dos registros e os "equipamentos e meios de transmissão cultural e documental” (ARAÚJO, 2015, p. 125).

O percurso inicial para o reconhecimento e validação da Bibliografia pode ser identificado na formação da Europa Moderna, espaço-tempo no qual buscava-se formas para a tratamento da organização e representação dos saberes, atividades desenvolvidas desde a antiguidade e o medievo. Deste modo, no início da era moderna, foram formuladas as primeiras reflexões sobre a Bibliografia, estas impulsionadas pela expansão da figura dos humanistas, os quais eram "interessados pelos textos antigos e pelos modos em que os mesmos deveriam ser organizados". Dentre os humanistas, "muitos se dedicaram não só à classificação dos seres, mas também dos saberes” (ARAÚJO, 2015, p. 127). Conforme apresentado por Araújo (2015),

Nos bibliógrafos modernos havia uma postura de dissecação dos elementos das ciências naturais que se transferiu para a dissecação do conhecimento, constituindo-se a ideia de uma anatomia do conhecimento (ARAÚJO, 2015, p. 127).

Nessa conjuntura, é que se observa, pela prática do bibliógrafo Conrad Gesner, a preocupação "com os livros em si e com o seu uso", o que aponta para a "dimensão mediadora" da Bibliografia (ARAÚJJ, 2015, p. 135).

Pela consideração de Araújo (2015, p. 136) de que a obra Bibliotheca Universalis (1545-1555) é um produto cultural e documentário, indica-se o movimento da Bibliografia a partir e sobre o documento. Em um aspecto, por arrolar elementos "da cultura manuscrita e impressa" e carregar, implicitamente, 
[...] uma profunda reflexão descritiva e semântica sobre os documentos e os saberes, o que contribuiu sobremaneira à configuração histórica e conceitual da Bibliografia enquanto disciplina (ARAÚJO, 2015, p. 136).

Em outro, por estruturar as bases do exercício bibliográfico de forma "quase atemporal às atividades bibliográficas, documentais e informacionais", o que permite a reflexão sobre a regularidade e manutenção dos atos "de mapear, registrar e representar, descritiva e semanticamente os documentos" (ARAÚJO, 2015, p. 136-137). Tais aspectos, sugerem, preliminarmente, um continuum bibliográfico, referencial para as possibilidades de manutenção do "gesto bibliográfico" na contemporaneidade.

Conforme estudo realizado por Saldanha (2015), a partir do pensamento de Gabriel Peignot e da análise conceitual da obra Dictionnaire Raisonné de Bibliologie (1802), é possível pontuar a relevância histórica, política e científica da Bibliografia no contexto das revoluções contemporâneas à sua formalização, que compreendem os séculos XVIII e XIX. Ademais, assinalar os elementos que conduzem à sujeição da Bibliografia pela Bibliologia e, posteriormente, pela Documentação.

Saldanha (2015, p. 150) apresenta que em toda a referida obra, Peignot esteve preocupado "com a definição de uma ciência que trata de organizar a massa de produtos da ciência". Ao considerar apenas este produto como amostra, o autor constata que houve "tanto uma preocupação reflexiva (definir um campo do conhecimento), quanto sistemática e descritiva (demonstrar os mais diversos meios de execução desta epistême)". Todavia, conforme tratado por Robert Estivals (2010 apud SALDANHA, 2015), pelo caráter enciclopédico deste vasto domínio epistemológico, verificam-se as tentativas de redução e limitação do pensamento epistemológico de Peignot. Deste modo, deve-se pontuar que

As descrições empíricas e a preocupação com a identificação dos "modos de fazer" dentro de diferentes verbetes, apontam para uma visão metodológica que aproxima Peignot de uma abordagem também semelhante aos métodos bibliográficos otletianos e da geração da Revue de Bibliologie, de onde parte o pensamento estivalsiano. Em outras palavras, julgamos ser possível ver, tanto a figura enciclopédica do Século das Luzes 
quanto o metodólogo empírico-descritivo e sistemático do Oitocentos no perfil intelectual peignotiano (SALDANHA, 2015, p. 150).

Peter Burke (2003), assim como Saldanha (2015), possibilitam a compreensão da conjuntura sócio-epistêmica da França no século XVIII, a partir da consolidação da distinção entre os campos de domínio do conhecimento pelo Estado, Igreja e Ciência.

Pela "mudança estrutural da Teoria do Conhecimento como epistemologia vigilante" verifica-se, nos encaminhamentos da obra de Peignot,

[...] uma espécie de "continuação" ao processo de "desnaturalização" do pensamento filosófico e teológico promovido pela Encyclopedie [Diderot e D'Alambert] e de fundamentação de um novo modo bibliográfico de se fazer ciência (SALDANHA, 2015, p. 151).

A obra Dictionnaire Raisonné de Bibliologie (1802), dedicada à ciência bibliográfica, apresenta preocupações quanto "a classificação e organização dos conhecimentos existentes", aprofundando a "articulação entre linguagem e materialidade" e destacando "a necessidade de desenvolvimento de novos saberes empíricos dedicados à organização de todos os saberes ainda por vir e seus produtos linguístico-materiais" (SALDANHA, 2015, p. 151).

Tais apontamentos indicam a condição ativa da Bibliografia, ao menos até o início do século XIX, no campo das relações entre saber/poder/fazer a partir e sobre o documento.

Esses movimentos também podem analisados tendo como base as colocações de Foucault (2005). Conforme apresentado pelo autor, entre os séculos XVII, XVIII e XIX foram estabelecidas novas formas de poder, 0 disciplinar e o científico.

Grigoleto e Murguia (2015), ao observarem estas transformações pela perspectiva dos agenciamentos a partir e sobre o documento, analisam as formas de utilização deste objeto pelo e para o poder. Neste sentido, apresentam que na configuração do poder disciplinar, entre os séculos XVII e XVIII, foram estabelecidos o discurso da ordem, o código da normalização, a episteme histórica e o discurso histórico. 
Os autores indicam que, a partir do século XVIII, houve o disciplinamento dos saberes pelo Estado a partir da articulação das operações de "seleção, normalização, hierarquização e centralização dos saberes", o que refletiu na configuração do poder científico. Desde o século XIX, pela regra da ciência, pela episteme histórica e científica, o documento passou a ser concebido "como objeto de saber, delimitado de forma sistematizada e orgânica", sendo "o ponto inicial e imprescindível para o conhecimento científico do passado". Em meio a esta conjuntura, no âmbito da Arquivologia, a noção de documento de arquivo e o princípio de respeito aos fundos, proposto por Natalis de Wailly em 1841, demonstram a harmonização do entendimento sobre o documento "com o dispositivo de poder da ordem" (GRIGOLETO; MURGUIA, 2015, p. 04-05).

É interessante notar, nesse percurso, alguns discursos pronunciados sobre a Bibliografia. Reuben A. Guild, no artigo "Bibliography as Science” (1896), apresenta que,

Devido aos muitos devotos da bibliografia, especialmente na França, tem-se exagerado o valor da prática bibliográfica para muito além da posição que lhe seria coerente na escala do conhecimento humano. Escritores como Peignot e Achard apresentam a bibliografia como a maior das ciências, incluindo, na verdade, todas as outras. Nada certamente pode ser mais absurdo do que observá-la sob esta luz meramente porque ela trata dos livros, e porque os livros são veículos de toda sorte de conhecimento. Aliás, esse é o único fundamento que se encontra para estas extravagantes representações, que tendem, como em qualquer outro caso de pretensões exageradas, expor ao ridículo um assunto que, quando sua natureza e objetos são corretamente definidos, não deixará de parecer importante como a serva da literatura, por assim dizer, e um apoio essencialíssimo para a ciência e a arte (apud ALVARES JUNIOR; SALDANHA, 2017, p. 201).

Por meio desta colocação, verifica-se certo deslocamento da condição da Bibliografia em seu saber/poder/fazer a partir e sobre o documento. Em um aspecto pelas conjunturas funcionais e estruturais de um momento histórico. Em outro, pelas diferentes abordagens da Bibliografia no mundo francófono e no mundo anglófono.

Compreende-se, então, que a partir do século XIX, alguns movimentos e conjunturas indicam as tentativas de deslocamento da Bibliografia pelo 
documento. Ou seja, novas concepções de documento, a emergência de campos de saber/poder/fazer a partir e sobre o documento, as diversas abordagens do vir a ser do documento pela Documentação reordenaram as condições de e para visibilidade da Bibliografia.

Assim, o que se coloca para reflexão em meio a estas emergências, é a maneira como alguns discursos científicos começaram a ser institucionalizados, por vezes, sem alçar aos fundamentos, práticas, regularidades e estabilidades de um saber/fazer norteador de suas emergências e possibilidades de continuidade.

Essas estruturações auxiliam nos entendimentos sobre os enfrentamentos e as lutas que certas ordenações funcionais e organizações sistemáticas de saberes começaram a travar. Ou seja, as ordenações estabelecidas entre a Bibliologia e a Bibliografia e os campos de disputas pelo saber/poder/fazer entre a Bibliografia e a Documentação.

Conforme demonstrado por Saldanha (2015, p. 162), desde Peignot começou a ser construída uma ampla visão da Bibliografia, compreendida em seus aspectos analítico e prático. O pensamento de Peignot indica, em meio a um jogo curricular, a Bibliografia como Teoria Geral da Bibliologia. A Bibliografia teria "um lugar epistemológico por excelência" na medida em que "[...] envolve os demais saberes (ou ciências) da Bibliologia", sendo "[...] também uma epistême distinta, dedicada à compreensão do livro pelo livro, mais do que sua descrição, como a leitura etimológica pode indicar à primeira vista".

Paulatinamente, algumas ordenações passaram a sugerir que a Bibliografia não se fundamentaria como um campo científico, mas ocuparia uma posição metacientífica, o que "lança a 'submissão' de uma certa produção epistêmica sobre 'outra ciência'". O pensamento bibliográfico passou a ser tomado como uma ferramenta, não como um saber independente; mas como um protossaber da Biblioteconomia, da Documentação e da Ciência da Informação (SALDANHA, 2015, p. 165).

Saldanha (2015) sugere que tais entendimentos podem ser compreendidos, dentre outros aspectos, por uma questão de ordem terminológica, que direciona de um lado 
[...] a busca racional por uma terminologia científica adequada para nomear um campo do conhecimento e, de outro, a necessidade permanente de revisão terminológica como solução para processos sócio-históricos de desenvolvimento de um campo, independentemente de seu conceito geral, o que leva até uma procura terminológica que, ao contrário, beira à irracionalidade (SALDANHA, 2015, p. 162-163).

Pelas reflexões do autor sobre o percurso para a hierarquização da Bibliografia dentro a Bibliologia identifica-se o primeiro movimento para sujeição da Bibliografia. Em meio a este processo, a produção epistêmica da Bibliografia, "que antecipa todas as questões do campo e que inicia seu desenho conceitual e curricular no século XIX", é, de certo modo, obscurecida em detrimento de nomenclaturas e significantes, "como se esses fundassem ciências, e não os homens, suas ideias e seus discursos" (SALDANHA, 2015, p. 165).

O segundo movimento para sujeição da Bibliografia pode ser verificado desde o percurso de Paul Otlet para cunhar e fundamentar entendimentos diferenciais sobre o documento e o ato de documentar. Neste processo, e ao longo do Traité de Documentation (OTLET, 1934), o autor opera no sentido de "ampliar os estudos bibliológicos, a prática bibliográfica e os fazeres e normas praticados em bibliotecas, todos pautados essencialmente no livro e demais escritos" (ORTEGA; SALDANHA, 2017, p. 5).

Se entre Peignot e Otlet fundamentou-se "a construção da primeira tentativa de reflexão epistemológica da organização dos saberes", desde Otlet as ordenações funcionais e as organizações sistemáticas levaram a sujeição do saber/poder/fazer da Bibliografia a partir e sobre o documento (SALDANHA, 2015, p. 154). Isso se conforma seja pela manutenção do reconhecimento e validação do poder/fazer da Bibliografia dentro das configurações da Documentação; seja pelo obscurecimento de seu poder/saber como campo qualificado do conhecimento e da ciência.

A Documentação, pelo empreendimento de Paul Otlet, passou a ser estruturada no sentido de reconhecimento, validação e institucionalização como "o saber/fazer" qualificado, na hierarquia do conhecimento e das ciências, a partir e sobre o documento. Em meio a esta estruturação, "blocos de saberes históricos" que estavam presentes foram "disfarçados no interior dos conjuntos 
funcionais e sistemáticos" (FOUCAULT, 2005, p. 11). Por estes contornos, a potência da Bibliografia foi mascarada em certas conjunturas, mas não eliminada, o que aponta para os movimentos de insurreição, os quais serão abordados pelos seguintes encaminhamentos: gesto bibliográfico e mediações.

\section{A BIBLIOGRAFIA E O DOCUMENTO COMO DISPOSITIVOS DE SABER/PODER/FAZER: A INSURREIÇÃO PELO GESTO BIBLIOGRÁFICO E PELA MEDIAÇÃO}

Pelas epistemes histórica e científica, foi possível acompanhar o uso que a Documentação fez das bases epistemológicas de conjunturas contemporâneas para alçar a sua fundamentação. Tendo em vista o lugar que a Bibliografia passou a ocupar no âmbito da Documentação, constata-se que esta foi alocada em consideração aos seus produtos. Ou seja, aos produtos resultantes das atividades de "produção de repertórios bibliográficos". Para tanto, utilizou-se de métodos e instrumentos próprios para o "tratamento de conteúdos temáticos e das partes dos documentos", considerando a ampliação da diversidade documental (ORTEGA; CARVALHO, 2017, p. 40).

Como Ortega e Carvalho (2017) expõem, a partir de Meneses Tello (2007), por esta característica do fazer bibliográfico,

[...] a Bibliografia manteve sua autonomia frente à
Documentação, como podemos observar em alguns programas
de ensino, na atuação das bibliotecas nacionais e na
continuidade das publicações e outras ações pelas sociedades
bibliográficas criadas no final do século XIX e início do XX na
Inglaterra, Estados Unidos e Canadá (ORTEGA; CARVALHO,
2017, p. 40).

Os encaminhamentos de Gabriel Peignot são retomados pelas autoras para explicitarem que o sistema bibliográfico pode ser entendido como um "dispositivo que deve funcionar como proposta de percurso cognitivo sobre documentos" (ORTEGA; CARVALHO, 2017, p. 42). Todavia, advertem que para considerar a contribuição da Bibliografia faz-se necessário ponderar que se trata de um campo finalístico, o qual depende para sua existência, "de fundamentação científica de cunho teórico, técnico, tecnológico e pragmático" (ORTEGA; 
CARVALHO, 2017, p. 43). Nestes termos, o trabalho bibliográfico é "aquele que se ocupa de referenciar o conhecimento produzido por meio de sistemas, serviços e demais ações que possibilitem o uso qualificado da informação" (ORTEGA; CARVALHO, 2017, p. 43).

As autoras, ao analisarem o papel da Bibliografia na construção do conhecimento em Ciência da Informação, apresentam alguns indicativos para o início das reflexões sobre a Bibliografia e o documento como dispositivos de saber/poder/fazer.

Até o presente momento, buscou-se entendimentos sobre as alocações e os agenciamentos da Bibliografia e do documento, movimentos que indicaram os processos para a sujeição da Bibliografia. Neste percurso, foi possível a verificação do documento como dispositivo na medida em que este passou a agenciar sobre a Bibliografia em função dos vetores de forças estabelecidos em meio às relações de saber/poder/fazer fundamentados, em especial, pela Documentação.

Cabe esclarecer que, na estratégia do pensamento de Foucault, "dispositivo" é um termo técnico decisivo e foi pronunciado pela primeira vez em entrevista no ano de 1977, a qual consta na obra "Dits et écrits III" (1994), para referir-se a

[...] um conjunto absolutamente heterogêneo que implica discursos, instituições, estruturas arquitetônicas, decisões regulamentares, leis, medidas administrativas, enunciados científicos, proposições filosóficas, morais, filantrópicas, em resumo: tanto o dito como o não dito, eis os elementos do dispositivo (FOUCAULT, 1994, p. 301 apud AGAMBEN, 2009, p. 28).

A partir deste entendimento, o documento como dispositivo aponta para a condição do objeto/agente/documento que redefine o lugar institucional do saber/fazer da Bibliografia, potencialidade adquirida pelos discursos, enunciados e proposições científicas que se definiram em meio às formas de relações de poder conduzidas pela Documentação.

Agora, pelos encaminhamentos propostos por Ortega e Carvalho (2017) pelo viés da Ciência da Informação, encontram-se elementos para a construção 
de entendimentos sobre a Bibliografia como dispositivo a partir de outras formas de relações: a Bibliografia agindo sobre o objeto/documento. Por esta perspectiva, o gesto bibliográfico emerge como vetor de força e a mediação como dispositivo, na medida em que articula os jogos e as relações de poder entre a Bibliografia e o documento.

Crippa (2015a, p. 01), ao tratar a arte da Bibliografia, considerando as ferramentas históricas, problemas metodológicos e práticas contemporâneas, apresenta que esta "[...] se ocupa de todos os textos registrados", bem como da descrição, produção e uso dos documentos. Por meio desta concepção, é possível afastar os "limites impostos por sua redução no espaço disciplinar", uma vez que "abrange um conjunto de disciplinas correlacionadas".

Em continuidade às análises dos trabalhos apresentados no I Seminário Internacional "A Arte da Bibliografia", realizado em 2014, a autora destaca que a Bibliografia não deve ser tratada como "uma disciplina marginal e auxiliar, voltada unicamente para a realização de inventários e para a interpretação restrita de dados editoriais formais". Ao contrário, indica que esta pode ser reconhecida como uma disciplina central na medida em que fornece elementos

[...] para o entendimento das formas através das quais uma comunidade "informa" e produz sentido em suas experiências, com base nas atividades de uma descrição e análise que se tornam designação dos conhecimentos (CRIPPA, 2015a, p. 02).

A questão do espaço-tempo, pela perspectiva do continumm, indica a abrangência de ideias voltadas a organização do conhecimento. Deste modo, entender o agenciamento da Bibliografia sobre o documento vai no sentido de colocar as suas potencialidades como dispositivo de saber/poder/fazer. Esta possibilidade direciona, portanto, a Bibliografia agindo sobre o documento em diferentes dimensões e não sendo agenciada pelo documento mediante as alocações impostas por determinados campos de saber/poder/fazer.

A noção de continuum, advinda do Modelo Records Continuum proposto no âmbito dos estudos dos praticantes dos saberes arquivísticos australianos, auxilia na reflexão sobre os encaminhamentos da Bibliografia com base em alicerces que conduzem aos movimentos para insurreição. Em especial, 
considerando-se as relações complexas, múltiplas e fluidas através do espaçotempo, as quais ultrapassam os limites dos lugares institucionais. Por uma visão multicontextual, que abarca elementos sociais, culturais, funcionais, documentais, técnicos e tecnológicos, fica mais compreensível os processos de permanências e mudanças no âmbito da Bibliografia (MCKEMMISH, 2017).

Por este encaminhamento, dialoga-se com os entendimentos de Crippa (2015b), na medida em que a autora aborda questões retrospectivas e prospectivas direcionadas ao campo da informação a partir de aspectos conceituais. Em sua análise, este campo

[...] muitas vezes, independe das temporalidades, mas se conectam, de maneira mais adequada, aos problemas que a interferência das tecnologias resolve de maneira mais eficiente, mas basicamente preservando a natureza do "gesto bibliográfico" na contemporaneidade (CRIPPA, 2015b, p. 112).

Pelo estudo da bibliografia de Cassiodoro, Institutiones Divinaruam Litterarum, Crippa (2015b, p. 113) apresenta que no percurso deste intelectual podem ser encontradas preocupações centrais e atuais da Ciência da Informação, tais como: "o gesto de devolver os traçados do conhecimento, seus registros materiais com suas marcas e a representação dos conteúdos documentários". Isso demonstra, pelo gesto bibliográfico, certas regularidades no decurso de permanências e mudanças no âmbito da Bibliografia, na medida em que o gesto é concebido como o alicerce de um dispositivo, a mediação.

Como colocado por Crippa (2016, p. 29), a Bibliografia pode ser vista "como expressão de saberes e de fazeres que merecem ser estudados no plano do saber fazer, na lógica 'artesanal". Isto porque, "o bibliógrafo, como artifex, como artífice, 'molda' as ferramentas de seleção e acesso ao conhecimento". Neste aspecto, é que se constitui a "necessidade de identificar seus fazeres como "gestos"'.

A partir de um ponto de vista conceitual, Crippa (2016, p. 32) estabelece a condição original da Bibliografia como uma tecnologia, "na medida em que seus 'produtos' se realizam dentro de um conjunto de regras ligadas à Retórica, isso é, a sua técnica/arte". Conforme os encaminhamentos da autora, deve-se considerar as dinâmicas e as transformações das tecnologias, as quais afetam 
as formas de racionalidade que passam a ser tecnológicas e não mais individuais.

Neste ponto é que se constatam também mudanças no âmbito da Bibliografia, pois as tarefas e funções desempenhadas pelos indivíduos são alteradas pelo estabelecimento de padrões externos. A "técnica", passa a adquirir a conotação "corrente do termo, que é de nunca supor interpretações "artísticas" ou individuais". Tem-se, portanto, um novo entendimento sobre "os próprios avanços científicos", do mesmo modo "o comportamento dos atores sociais adquire a racionalidade do processo do sistema, que tem um conteúdo social definido" (CRIPPA, 2016, p. 34).

Quando o gesto bibliográfico se torna, por sua vez, racionalidade tecnológica, a lógica da criação dos instrumentos bibliográficos é subvertida: a organização deve adaptar-se ao complexo dos dispositivos dados e à sua estruturação, conformando-se ao sistema, quebrando a possibilidade de seu fazer enquanto Arte para se tornar treinamento técnico. Na lógica da busca de eficiência, a bibliografia corre o risco de integrar o perfil tecnológico articulado ao imperativo científico, desistindo assim de sua autonomia racional (CRIPPA, 2016, p. 36).

Agamben (2008) para abordar o gesto recorre, inicialmente, as colocações de Varrão, que o escreve na esfera da ação, distinguindo as noções do agir (agere) e do fazer (facere). Deste modo, apresenta que é possível fazer algo e não agir. Para exemplificar esta colocação, utiliza o drama, pelas perspectivas textual, de exibição e política. Assim, esclarece que o poeta o faz, mas não age; que o ator age, mas não faz; e que o imperador nem faz, nem age, mas suporta.

Posteriormente, para apresentar de que maneira uma ação é assumida e suportada, recorre aos entendimentos de Aristóteles para quem o gênero do agir (da praxis) difere-se do fazer (do poiesis). O primeiro é compreendido como um fim sem meios e o segundo como um meio em vista de um fim. Ao lado destes gêneros é identificado um terceiro, que aponta para o gesto rompendo a "falsa alternativa entre fins e meios que paralisa a moral e apresenta meios que, como tais, se subtraem ao âmbito da medialidade, sem por isso tornarem-se fins" (AGAMBEN, 2008, p. 13). 
O gesto seria, então, a "exibição de uma medialidade, o tornar visível um meio como tal". Em outros termos, "é a esfera não de um fim em si, mas de uma medialidade pura e sem fim que se comunica aos homens". Uma "finalidade sem fim", pela concepção de Kant, indicaria a "potência do gesto que o interrompe no seu próprio ser-meio e, apenas assim o exibe, faz de uma res uma res gesta" (AGAMBEN, 2008, p. 13).

A partir destas perspectivas, Menezes (2015) coloca que em Paul Otlet

[...] "a bibliografia é um meio, não um fim" (OTLET, 2007, p. 286); o fim é a "bibliologia ou documentação" (OTLET, 2007, p. 9). O gesto bibliográfico em Otlet $(2007$, p. 288) é um meio, "nunca se acaba: deve continuar" e fazendo referência ao Eclesiastes 12:12 diz: "não há limite para fazer livros". A bibliografia é "a base de toda documentação" (OTLET, 2007, p. 286) um meio para um fim - a ciência geral do documento (bibliologia) baseada no "livro universal": "summa summarum", a "obra". Com esta definição Paul Otlet acaba por inconscientemente cercear o potencial emancipatório do seu projeto bibliográfico universal, fundado num dos pilares da modernidade, 0 uso público da razão (MENEZES, 2015, p. 176).

O autor, ao tratar sobre a inter-relação entre a Bibliografia e o estatuto cognitivo das coisas, também sugere que a reinterpretação da "bibliografia física", a partir da turn linguist, permite entendimentos mais férteis quanto a construção social de evidências (MENEZES, 2015).

Nestes termos e pelos encaminhamentos das reflexões pautadas na Teoria do Documento e na Quinta Dimensão do Modelo Records Continuum, a Bibliografia pode ser analisada pela perspectiva do gesto bibliográfico e da cultura-como-evidência, o que encaminha para a mediação no sentido de condição de e para visibilidade.

Portanto, analisa-se a Bibliografia e o documento como dispositivos não destacando meios e finalidades, mas as condições de sua existência e manutenção diante de diferentes demandas e problemáticas, por exemplo, as colocadas pelas tecnologias.

Para Crippa (2016, p. 37),

[...] a bibliografia, enquanto arte (do fazer), precisa ser pensada para que não passe por uma simples adaptação às tecnologias, mantendo todos os cuidados para que suas práticas não sejam 
reduzidas a treinamentos com o escopo da manutenção do aparato.

A potência da Bibliografia e as potencialidades pelo gesto permitem a reflexão sobre os instrumentos e as interfaces que se estabelecem nos processos de mediação de saberes sujeitados, da competência e da ordem dos movimentos para sujeição e insurreição. Em decorrência, pode-se apontar para os processos de mediação, compreendidos tanto em relação aos objetos sobre os quais agencia quanto para a própria condição de existência e visibilidade de quem agencia. Ou seja, considera-se o gesto bibliográfico como alicerce de um dispositivo e a mediação como um dispositivo para produtos e processos.

Entende-se, pelo gesto bibliográfico, diferentes dimensões no espaçotempo, as marcas e os rastros de uma arte que não se restringe aos limites disciplinares e científicos, mas suporta, em diferentes temporalidades, as demandas emergentes na medida em que sustenta pontos de referência, os quais são articulados e explicitados pelas mediações.

O espaço-tempo da Bibliografia e do documento pode ser observado nas dimensões em que cada qual se fundamentou como dispositivo. Os saberes e fazeres em meio a conjunturas que definiram certas condições de poder.

Ressalta-se que a Bibliografia não está distante dos objetos sobre os quais agencia, sofrendo influência dos mesmos e das diversas dinâmica envoltas nos procedimentos e processos de/para (re)configurações destes.

Tais relações e jogos de poder entre saberes e práticas delinearam os lugares institucionais, os embates e as formas de agenciamentos, movimentos que puderam ser reconhecidos por meio de suas validações em certos espaços e tempos. Pelo entendimento do lugar, do espaço e do tempo da Bibliografia e do documento, foi possível a identificação de fissuras e dimensões múltiplas, o que permitiu a verificação de emergências que impulsionaram o deslocamento da sujeição para a insurreição da Bibliografia.

\section{CONCLUSÕES}


Ao longo do percurso para compreensão dos movimentos de sujeição e insurreição da Bibliografia, buscou-se elementos para analisar conjunturas que se colocaram em meio a transformações pautadas pelas epistemes histórica e científica. A noção de continuum, pelas perspectivas de manutenção e inovação, auxiliou na verificação de certos traçados no espaço-tempo. Assim, o espaçotempo neste trabalho correspondeu as condições geográficas e cronológicas bem como aos movimentos para (re)alocações de aspectos racionais, regulares, materiais, estáveis, localizáveis e institucionais. Enfim, aos deslocamentos dos lugares e da ordem. Considerou-se, portanto, os saberes e fazeres a partir e sobre a Bibliografia e o documento, com base em abordagens documentais e informacionais por meio de múltiplas dimensões.

As formas e os limites de e para a visibilidade da Bibliografia, pelos aspectos de seu saber/poder/fazer a partir e sobre o documento, correspondem aos agenciamentos direcionados aos movimentos para a naturalização e desnaturalização do tratamento da organização e representação dos saberes. A dimensão mediadora da Bibliografia, pelo gesto bibliográfico, estabelece um continuum nos processos de desnaturalização. Em outras palavras, a Bibliografia tomada como um saber/fazer próprio é que conduz a transposição de ordenações e sistematizações que levaram a sua sujeição, indicando as suas potencialidades para recolocar sua autonomia racional.

Por estes e demais aspectos abordados no texto, indica-se que a Bibliografia e o documento são dispositivos de saber/poder/fazer, são dispositivos de mediação que operam e são operacionalizados em dados campos de embate. Nesse sentido, é possível observar a Bibliografia pelas potências de seu poder/fazer, fundamentado na materialidade, regularidade, estabilidade, continuidade e descontinuidade (no sentido de "inovação") de suas práticas. E pelas potências de seu poder/saber, que apresenta deslocamentos que conduzem para a sua insurreição.

Como encaminhamento final, destaca-se o lugar institucional e o espaçotempo das edições do Seminário Internacional "A Arte da Bibliografia" como parte do processo de insurreição da Bibliografia na medida em que são configuradas condições para reconduzi-la em seu próprio discurso e em seus próprios efeitos 
de saber/fazer. A Bibliografia é recolocada no campo de batalha entre os saberes e contra os efeitos e limites impostos por certos campos e discursos, os quais foram reconhecidos, validados e institucionalizados como científicos em meio a fundamentações de poder.

\section{REFERÊNCIAS}

AGAMBEN, G. Notas sobre o gesto. Artefilosofia, Ouro Preto, n. 4, p. 9-14, jan. 2008. Disponível em:

<http://www.periodicos.ufop.br/pp/index.php/raf/article/view/731/687>. Acesso em: 20 jan. 2018.

2009.

O que é o contemporâneo? E outros ensaios. Chapecó: Argos,

ALVARES JÚNIOR, L. de S.; SALDANHA, G. S. A bibliografia como ciência.

[Tradução do artigo de GUILD, R. A. Bibliography as science. American Library Journal, v. 1, n. 02-03, p. 67-69, nov. 1876.]. Perspectivas em Ciência da Informação, v. 22, número especial, p. 199-202, jul. 2017. Disponível em: <http://www.scielo.br/pdf/pci/v22nspe/1413-9936-pci-22-spe-00199.pdf>. Acesso em: 10 set. 2017.

ARAÚJO, A. V. de F. Pioneirismo bibliográfico em um polímeta do séc. XVI: Conrad Gesner. Informação \& Informação, Londrina, v. 20, n. 2, p. 118-142, maio/ago. 2015. Disponível em:

<http://www.uel.br/revistas/uel/index.php/informacao/article/view/23127/pdf_62> . Acesso em: 10 set. 2017.

BURKE, P. Uma história social do conhecimento: de Gutenberg a Diderot. Rio de Janeiro: Jorge Zahar Ed., 2003.

CRIPPA, G. A arte da Bibliografia: ferramentas históricas, problemas metodológicos e práticas contemporâneas. Informação \& Informação, Londrina, v. 20, n. 2, p. 01-06, maio/ago. 2015a. Disponível em: <http://www.uel.br/revistas/uel/index.php/informacao/article/view/23134/17340>. Acesso em: 29 out. 2017.

. Cassiodoro e as Institutiones Divinarum Litterarum como fonte histórica para a discussão sobre práticas bibliográficas e organização do conhecimento. Informação \& Informação, Londrina, v. 20, n. 2, p. 86-117, maio./ago. 2015b. Disponível em:

<http://www.uel.br/revistas/uel/index.php/informacao/article/view/23126/pdf_61> . Acesso em: 29 out. 2017. 
. Entre arte, técnica e tecnologia: algumas considerações sobre a bibliografia e seus gestos. InCID: Revista de Ciência da Informação e Documentação, Ribeirão Preto, v. 7, número especial, p. 23-40, ago. 2016. Disponível em: <http://www.revistas.usp.br/incid/article/view/118748/116231>. Acesso em: 10 set. 2017.

FOUCAULT, M. Em defesa da sociedade. São Paulo: Martins Fontes, 2005.

GRIGOLETO, M. C.; MURGUIA, E. I. As bases epistemológicas do patrimônio institucionalizado. Tendências da Pesquisa Brasileira em Ciência da Informação, v. 8, n. 2, p. 1-19, jul./dez. 2015. Disponível em: <http://www.brapci.inf.br/index.php/article/download/43727>. Acesso em: 25 jan. 2018.

LUND, N. W. Document Theory. ARIST, v. 43, n. 1, p. 1-55, 2009.

MCKEMMISH, S. Recordkeeping in the Continuum. In: GILLILAND, A. J.; MCKEMMISH, S.; LAU, A. J. (Eds.). Research in the Archival Multiverse. Victoria: Monash University Publishing, 2017, p. 122-160.

MENEZES, V. O gesto bibliográfico e a modernidade. Informação \& Informação, Londrina, v. 20, n. 2, p. 168-183, maio/ago. 2015. Disponível em: <http://www.uel.br/revistas/uel/index.php/informacao/article/view/23129/pdf_64> . Acesso em: 29 out. 2017.

ORTEGA, C. D.; CARVALHO, M. da C. O papel da Bibliografia na construção do conhecimento em Ciência da Informação: o caso da Escola de Ciência da Informação da UFMG. Perspectivas em Ciência da Informação, v. 22, número especial, p. 36-64, jul. 2017. Disponível em:

<http://portaldeperiodicos.eci.ufmg.br/index.php/pci/article/view/3255/1951>. Acesso em: 29 out. 2017.

ORTEGA, C.; SALDANHA, G. S. A noção de documento desde Paul Otlet e as propostas neodocumentalistas. In: Encontro Nacional de Pesquisa em Ciência da Informação (ENANCIB), 18, 2017, Marília. Anais eletrônicos... Marília: UNESP, 2017. Disponível em: $<$ http://enancib.marilia.unesp.br/index.php/xviiienancib/ENANCIB/paper/viewFil e/163/722>. Acesso em: 09 nov. 2017.

OTLET, P. Traité de documentation: le livre sur le livre, théorie et pratique. Editiones mundaneum, 1934.

SALDANHA, G. S. A posição da Bibliografia na epistemologia de Peignot no setecentos. Informação \& Informação, Londrina, v. 20, n. 2, p. 143-167, maio./ago. 2015. Disponível em:

<http://www.uel.br/revistas/uel/index.php/informacao/article/view/23128/pdf_63> . Acesso em: 10 set. 2017. 


\title{
THE SPACE-TIME OF BIBLIOGRAPHY AND DOCUMENT: REFLECTIONS ON EPISTEMS AND MEDIATIONS
}

\begin{abstract}
Introduction: The paper addresses the space-time of the Bibliography and Document from the notion of subjugated knowledge discussing the historical and scientific epistemes that are constitutive paths of knowledge and practices. Objective: The purpose of the paper is to discuss the issue of rationality and regularity in the processes of institutionalization; and to think over the exploration of Bibliography and Document taking into account the processes of recognition, validation, maintenance and possibilities of allocation. Methods: the method used in the research was a literature review on Document Theory and Records Continuum Theory. Results: the paper highlights the subjugation of Bibliography through functional and systematic organization of Bibliology and Documentation. Conclusions: Through the observation of material and relational characteristics (products and processes), the research points to the understanding of the Bibliography and Document as apparatus/dispositifs of power/knowledge (mediation dispositifs/apparatus), having as a foundation the bibliographic gesture.
\end{abstract}

Descriptors: Bibliography. Document. Epistemology. Mediation. Bibliographic gesture.

\section{EL ESPACIO-TIEMPO DE LA BIBLIOGRAFÍA Y DEL DOCUMENTO: REFLEXIONES SOBRE EPISTEMES Y MEDIACIONES}

\begin{abstract}
RESUMEN
Introducción: Trata el espacio-tiempo de la Bibliografía y del documento a partir de la noción de saberes sujetados, dirigiendo entendimientos sobre las epistemes histórica y científica en el recorrido constitutivo de saberes y prácticas. Objetivo: Se pretende discutir la cuestión de la racionalidad y la regularidad en los procesos de institucionalización; y reflexionar sobre las potencialidades para la exploración de la Bibliografía y del documento, atentando para los recorridos de reconocimiento, validación, mantenimiento y posibilidades de asignaciones. Metodología: Se realizó una revisión de literatura basada en los enfoques de la Teoría del Documento y de la Teoría Records Continuum. Resultados: Destaca movimientos de sujeción de la Bibliografía por medio de ordenaciones funcionales y organizaciones sistemáticas de la Bibliología y de la Documentación. Conclusiones: Comprende la Bibliografía y el documento como dispositivos de saber/poder/ hacer (dispositivos de mediación) al observar las características materiales y relacionales (productos y procesos), teniendo como fundación el gesto bibliográfico.
\end{abstract}

Descriptores: Bibliografía. Documento. Epistemología. Mediación. Gesto bibliográfico.

Recebido: 10.05 .2018

Aceito: 25.08 .2018

Inf. Inf., Londrina, v. 23, n. 2, p. 78 - 97, maio/ago. 2018.

http://www.uel.br/revistas/informacao/ 